\title{
HISTORIA Y ELEGIA DE LOS DEPOSITARIOS DE FONDOS DE ADMINISTRACION LOCAL
}

\author{
por \\ Alejandro Nieto \\ Catedrático de Derecho Administrativo
}

SUMARIO: I. INTRODUCCION.-II. LA EPOCA LIBERAL: EL DEPOSITARIO, CLAVE DE LA ADMINISTRACION MUNICIPAL.-III. LA EPOCA MODERADA: APOGEO DE LA DEPOSITARIA.-IV. REVOLUCION Y RESTAURACION: DECADENCIA DEL DEPOSITARIO: 1. Causas. 2. Facultades fiscalizadoras De los Depositarios y Contadores. 3. De los Contadores proVINCIALES A LOS CONTADORES MUNICIPALES.-V. LA DICTADURA: DESARTICULACION FUNCIONAL Y REHABILITACION CORPORATIVA.-VI. LA SEGUNDA REPUBLICA: PERIODO DE AVATARES.-VII. FINAL.

\section{INTRODUCCION}

Resulta paradójico que en un Estado cuya Constitución (artículo 103.2) establece que "la ley regulará el estatuto de los funcionarios», existan grupos de éstos que no sólo carecen, al cabo de casi diez años, de un régimen jurídico que merezca el nombre de Estatuto sino que incluso ignoren su verdadera denominación y hasta pueda dudarse de su realidad como grupo o cuerpo especializado. Tal es el caso de los antiguos (¿o actuales todavía?) Depositarios de Fondos de Administración Local, cuyo estatuto tradicional ocupaba un lugar nítido en el ordenamiento jurídico y que ahora, deliberadamente desmantelado aquél, viven flotando entre 
dos mundos, como el alma de Garibay, sin encontrar un palmo de tierra firme en las leyes vigentes, que les asegure el presente $o$, al menos, les ofrezca una somera indicación sobre su porvenir.

A este respecto, la Ley de Bases de Régimen Local y el Texto Refundido constituyen un buen ejemplo de cómo las normas, cuando se encuentran cogidas en el fuego cruzado de intereses contrapuestos (en este caso, los defensores y los detractores a ultranza de un "cuerpo"), pueden acudir a locuciones gramaticales sibilinas en que arropar la ausencia de una decisión terminante. El viejo Cuerpo de Depositarios de Fondos de Administración Local se ha disuelto - esto es claro- en el magma impreciso de los funcionarios con habilitación de carácter nacional (art. 92.3 de la Ley Básica). Las Depositarías parecen haber desaparecido, aunque la Ley hable ocasionalmente de "Tesorerías". Las funciones que desempeñaban se mantienen sin transformaciones sustanciales. Pero los funcionarios titulares, denominados antes Depositarios de Fondos, ahora sobreviven con el barroco título de «funcionarios con habilitación de carácter nacional que desempeñan un puesto de trabajo específico que tenga atribuida la responsabilidad administrativa de las funciones de tesorería, que incluye el manejo y custodia de fondos y valores de la Entidad y la recaudación". Con esta fórmula el legislador ha conseguido su objetivo de ocultar sus verdaderas intenciones; pero hay que reconocer que ni el estilo ni la precisión normativa han salido ganando: ocultar lo que se quiere decir o disimular que no hay nada que decir resulta, en verdad, carga pesada para los redactores de una ley y más todavía para sus destinatarios e intérpretes.

Perdidos en las tinieblas legales, a donde les ha confinado la Ley 7 de 1985, los Depositarios de Fondos (si se nos permite emplear esta obsoleta denominación) viven en la espera de regresar a la claridad del ordenamiento jurídico; pero sus deseos tardan en realizarse. El Texto Refundido de 1986 fue la primera oportunidad perdida, aunque la demora no parecía grave, habida cuenta de que la Disposición Final $\left.1 .^{a}, c\right)$, imponía el plazo de un año para la publicación del nuevo Reglamento de funcionarios, en el que habrían de aclararse las dudas.

Pero se ha consumido este plazo, pasan los años, el Reglamento sigue sin aparecer, la confusión no se disipa y la desmoralización cunde, puesto que ya nadie sabe ni dónde está ni cuál va a ser su futuro y hasta surgen sospechas de si el Gobierno y el Gobierno 
se habrán olvidado de estos funcionarios. La degradación ha llegado en la actualidad a un nivel tan profundo que los Depositarios ya no reivindican derechos individuales o corporativos y se limitan a esperar que algún día, algún año, el Gobierno se acuerde de ellos para comunicarles, simplemente, si existen o no existen.

En el presente estudio se intenta dedicar un recuerdo elegíaco a la memoria de estos funcionarios, demostrando que su aparición no fue fruto del azar ni del capricho sino resultado de una necesidad funcional, que no puede desaparecer en las turbulencias de una política vesánica o ignorante. $\mathrm{Y}$ al final de este repaso histórico se indagarán las causas que han provocado la situación actual. Porque, a lo largo del examen histórico que va a realizarse, podremos comprobar que la evolución de los Depositarios de Fondos de Administración Local, ha sido siempre muy agitada, pero que en todo caso ha obedecido a motivos institucionales claros y confesados. Sólo en esta última etapa aparecen ocultos los motivos del cambio, que se intentarán dilucidar en el número final.

El Depositario es tan antiguo como el propio Ayuntamiento, puesto que no se comprende una Administración municipal mínimamente ordenada sin una regulación precisa de las funciones que hoy se llaman de Depositaría o Tesorería, y de sus correspondientes titulares. Así sucede desde el primer establecimiento del régimen constitucional, que es el punto de partida que se toma para el presente estudio, en el que se margina la época anterior, con objeto de no recargar estas páginas con alardes eruditos, ciertamente interesantes, pero que nada o muy poco contribuirían a los fines propuestos.

La historia de los Depositarios está, desgraciadamente, por hacer. Nadie se ha ocupado seriamente de ellos, y se da por supuesto (aparte de algunas referencias pintorescas a los siglos medievales) que empiezan en 1930, en 1924 o, a todo lo más, en la Ley municipal de 1877. Actitud que hace de ellos un fenómeno errático, como si hubieran salido del capricho del legislador, que les crea de la nada. Y, sin embargo, la historia demuestra exactamente lo contrario: arrancando de la primera Ley municipal de 1823, se constata una evolución apasionante y triste: la de unos funcionarios claves en la Administración Local que, marcados por un destino adverso, ven año tras año decrecer su importancia hasta llegar a la ambigua situación en que hoy se encuentran. Por así decirlo, la historia de los Depositarios es la historia de una decadencia continua e inexo- 
rable. Y el objetivo de este estudio es, no tanto la constatación del proceso como el análisis de las causas de tal tendencia y comprobar lo que de justificado, y no justificado, hay en todo ello.

A tal efecto, y para facilitar la inteligencia de la exposición, se periodiza el estudio en una serie de etapas, perfectamente diferenciadas, marcada cada una de ellas en mojones legislativos muy concretos.

Por lo demás, la historia completa de esta larga evolución puede resumirse en unos pocos datos sumamente esclarecedores $-\mathrm{y}$ aun imprescindibles- para comprender la situación actual de los Depositarios y, más todavía, de la peculiaridad orgánica de los Ayuntamientos españoles:

a) En un primer momento Depositarios y Secretarios (junto con los Alcaldes) constituyen el eje de la organización burocrática municipal, realizando íntegramente la gestión administrativa, bajo el control superior de la Corporación. De esta manera se dibuja un modelo rigurosamente paralelo al de las entidades locales del resto de Europa continental.

b) La segunda mitad del siglo $\mathrm{xIx}$, la ruina patrimonial de los Municipios (provocada fundamentalmente por la desamortización) y el acelerado proceso de descentralización estatal, rompen el modelo al introducir en él una pieza procedente de la Hacienda Pública -el Contador- que trasplanta violentamente a la Administración municipal los principios organizativos propios de la Administración del Estado. Con lo cual se produce una ruptura con el modelo anterior y, al tiempo, un abandono del anterior paralelismo europeo. A partir de este momento, los entes locales españoles van a seguir una vía propia, que se separa de la europea, para aproximarse al modelo de la Administración del Estado. El proceso - lineal durante más de un siglo y aparentemente irreversible- ha cambiado bruscamente de signo con la Constitución autonomista de 1978.

c) De hecho - y de forma un tanto paradójica- la presencia del Contador no desapodera al Depositario de sus facultades iniciales, que se superponen a las suyas. Pero, inevitablemente, con el tiempo va eliminándose esta inútil reduplicación en beneficio, por supuesto, del Contador (Interventor), que magnifica su papel a costa del Depositario, cuya figura se desdibuja en un repertorio desarticulado de funciones. 


\section{LA EPOCA LIBERAL: EL DEPOSITARIO, CLAVE DE LA ADMINISTRACION MUNICIPAL}

La primera Ley municipal española, de 2 de febrero de 1823, concede a los Depositarios una importancia excepcional, al montar toda la organización burocrática de los Ayuntamientos constitucionales sobre el binomio Secretario-Depositario, prácticamente en pie de igualdad, dentro cada uno de sus respectivas competencias.

El artículo 28 regula su nombramiento y funciones en los siguientes términos:

En los ocho primeros días de cada año nombrará el Ayuntamiento, a pluralidad absoluta de votos y bajo la responsabilidad de los nominadores, un Depositario, en cuyo poder entren directamente los caudales de propios y arbitrios, sin que por ningún motivo puedan percibirlos ni retenerlos los Alcaldes ni los demás capitulares. El mismo Depositario pagará los libramientos que se expidan, siendo extendido con las formalidades que están prevenidas.

El cargo, por lo demás, no está profesionalizado aún, en el sentido moderno de la palabra, y sería inimaginable otra cosa en unos momentos de reorganización global de los entes municipales de toda la Nación cuando el cuerpo social, y los estudios de la época, no permiten la formación técnica y súbita de varios miles de funcionarios. De aquí que el artículo 29 advierta, a renglón seguido, que «el Ayuntamiento podrá remover al Depositario y nombrar otro en su lugar cuando lo tenga por conveniente, aunque no haya cumplido el año".

Dos son, pues, las funciones iniciales del Depositario, a las que se añade, en el artículo 40, una tercera:

Dentro de los diez primeros días del mes de enero de cada año presentará el Depositario de propios y arbitrios las cuentas de estos fondos correspondientes al año anterior, extendidas con formalidad y justificación.

Estas cuentas expresan la situación financiera del Municipio y sirven para el control de la gestión del mismo, tal como determina el artículo 42, en el que se especifica la doble responsabilidad que de ellas puede derivarse: la del Depositario por un lado y, por otra parte, la de los capitulares que, de alguna manera, hayan producido una irregularidad: 
El Ayuntamiento examinará estas cuentas; y si hallase algunos reparos que oponer a ellas, los extenderá por escrito y comunicará el pliego que informe al Depositario, si los reparos versaren sobre omisión de cargo, falta de justificación $u$ otro artículo de que él deba responder; o a los capitulares del artículo anterior, si dichos reparos recaen sobre haber sido mal libradas algunas cantidades, sobre no haber tenido los fondos los debidos valores o sobre ciertos particulares de que puedan ser responsables los mismos capitulares.

En cuanto a su denominación, la ley habla inequívocamente de Depositario; pero en la práctica de la época se habla también de «tesorero» y de "mayordomo». (cfr. ORTIZ DE ZÚÑIGA: Práctica de Secretarios de Ayuntamiento, 1843, pág. 40).

Además del Depositario en sentido estricto -el Depositario de propios y arbitrios- existe otro completamente distinto, con funciones de receptor de los impuestos nacionales, cuya recaudación estaba encomendada a los Ayuntamientos. Aparece ya en los artículos 6 y 7 de la Instrucción de 18-10-1824, como antecedente inmediato de los actuales recaudadores, y en el artículo 9 de la Instrucción de 6-7-1828, bajo la denominación de «cobrador depositario", se le encomienda la "operación material de la cobranza».

\section{LA EPOCA MODERADA: APOGEO DE LA DEPOSITARIA}

El Gobierno moderado de 1845 mantiene, en la Ley municipal de 8 de enero, el esquema anterior, sin más variaciones que la de denominarlo, indiferenciadamente, «depositario o mayordomo" (artículo 108) y de apuntar la posibilidad de crear «un encargado de la intervención de los fondos del común donde sean necesarios» (artículo 79) - facultad que normalmente sigue manteniendo el Secretario (el art. 23 de la Instrucción de 20-11-1845 advierte expresamente que tiene la "calidad de interventor")-, aparte de regular sus finanzas.

Ahora bien, esta Ley sufre el mismo año un minucioso desarrollo en el Reglamento, de 16 de setiembre e Instrucción de 20 de noviembre, que perfila con precisión una figura que vive momentos de apogeo.

Por lo pronto, se detallan sus obligaciones, que se amplían - recogiendo, bien es verdad, la práctica administrativa ya consagradaa los siguientes extremos: 
- Custodiar los depósitos o valores que tenga en su poder (regla 8. ${ }^{a}$ de la Instrucción).

- Confeccionar las nóminas (regla 13 de la Instrucción).

- Llevar un libro de caja foliado y rubricado por el Alcalde, en el que sienta diariamente las cantidades que ingresen en su poder, con referencia a la carta de pago y cargaréme respectivo, y las satisfechas en virtud de libramientos, indicando el número de éstos (regla 17 de la Instrucción).

- Realizar los arqueos mensuales, junto con el Secretario y el Alcalde (regla $4 .^{\text {a }}$ de la Instrucción).

- Presentar las cuentas anuales, que comprenderán: en el cargo, la existencia que le quedó en fin del año anterior y las cantidades que haya recaudado durante el de la cuenta por los artículos de ingresos del presupuesto; y en su data, las satisfechas por los gastos del mismo (regla 12 de la Instrucción).

Esta cuenta -0 cuenta general - incluye también las de los establecimientos municipales, y es, en todo caso, distinta de la que simultáneamente debe presentar el Alcalde. Ambas cuentas son sometidas directamente al control de la Corporación y del Jefe político en los términos del artículo 9 del Reglamento:

En el mes de enero de cada año se presentarán al Ayuntamiento... las cuentas del Alcalde y del Depositario o mayordomo, correspondientes al año anterior. El Ayuntamiento las examinará y censurará en el mes de febrero y, dejando un ejemplar en el archivo de la Corporación, remitirá el Alcalde los otros dos al Jefe político.

Tan interesante como sus obligaciones, resulta, a nuestros efectos, la relación de sus facultades fiscalizadoras, que se superponen a las del Secretario, por cuyo ejercicio se le exige una responsabilidad concreta:

- No puede pagar cantidad alguna que no esté arreglada a las partidas del presupuesto, bajo cuyo concepto podrá negarse a pagar los libramientos del Alcalde, decidiendo en su caso la Comisión provincial las dudas y diferencias suscitadas con tal motivo.

- Cuando ocurra la construcción de obras o reparación de edificios, no puede satisfacer más cantidades que las expresadas en el pliego de condiciones bajo el que se hubiere hecho el remate y en los plazos que allí se hubiesen fijado (regla $8 .^{a}$ de la Instrucción). 
En la siguiente Ley municipal de 5-7-1856 no vale la pena detenerse, dada la brevedad de su vigencia y, sobre todo, porque reproduce el esquema anterior. Pero conviene recordar, al menos, la importancia que en ella van cobrando los «agentes para la recaudación de todas las rentas del Municipio» (arts. 218 y 219) así como el principio de que "todos los fondos municipales ingresarán precisamente en la Caja única que ha de tener el Ayuntamiento a cargo del Depositario" (art. 220).

En definitiva, dentro de la época isabelina nos encontramos con un Depositario fuerte, contrapunto del Alcalde, en cuanto ordenador de pagos, y del Secretario, en cuanto interventor, dotado de atribuciones muy amplias y formuladas normativamente con gran precisión: cobra, custodia, paga y rinde cuentas, con responsabilidad propia, que le diferencia de un simple cajero; sus cuentas, complementadas por las del Alcalde, cifran la actividad económica del Municipio y en el ejercicio de sus funciones fiscalizadoras, sus decisiones pueden bloquear las del Alcalde, elevándose en tal caso sus diferencias a una instancia superior para que las dirima.

\section{REVOLUCION Y RESTAURACION: DECADENCIA DEL DEPOSITARIO}

\section{Causas de la decadencia del Depositario}

La Revolución y la Restauración cambian, un tanto bruscamente, el panorama. En las Leyes municipales de 20-8-1870 y 2-10-1877 el Depositario abandona su protagonismo tradicional y resbala inequívocamente a una posición de segunda fila, cada vez más desdibujada: presionado, de un lado, por los recaudadores de contribuciones y, por otro, y sobre todo, por los contadores. Pero conste que tal proceso no se debe a razones ideológicas o del azar, sino que responde a dos causas muy concretas, que es fácil poner al descubierto.

En primer término, la decadencia de los Depositarios es consecuencia directa de la correlativa decadencia de la Hacienda patrimonial de los Municipios. Hasta entonces - y desde siempre- los Ayuntamientos habían nutrido sus presupuestos de las rentas de su patrimonio propio. Salvo excepciones, sus bienes eran suficientes, cuando no cuantiosos, para cubrir sus necesidades, y ya sabemos que su gestión pasaba por las manos del Depositario, que debía 
dar cuenta íntegra de ellos. Los impuestos llamados nacionales eran un simple complemento, cuya recaudación -cuantitativa y cualitativamente marginal (y sometida además a una permanente y durísima oposición de carácter incluso revolucionario)- se encomendaba a unos individuos, los recaudadores de impuestos, que, por las razones dichas, no desempeñaban un papel importante, sin que nada grave pudiera implicar, en sustancia, esta privatización del ejercicio de funciones públicas.

El fenómeno de la desamortización vino a alterar, sin embargo, el esquema. Los Ayuntamientos -también salvo excepciones- se empobrecieron súbitamente $\mathrm{y}$, perdiendo su autonomía, pasaron a depender de unas rentas tributarias ajenas, en el sentido de que eran autorizadas por el legislador del Estado. Lo que antes era complementario pasó a ser principal, cuando no único. Y los recaudadores de contribuciones pasaron, correlativamente, a un plano funcional superior, a costa naturalmente de los Depositarios, que habían perdido - junto con el patrimonio municipal- un área fundamental de gestión.

En segundo término, la misma causa de la desamortización originó una consecuencia refleja, que agravó aún más el deterioro de su posición. Al perderse la autonomía financiera y al magnificarse los impuestos de legitimación estatal, la Administración del Estado entendió, no sin congruencia, que su gestión debía ser controlada especialmente a través de unos funcionarios paralelos a los que estaban actuando a nivel estatal. Así es como aparecen -y se potencian progresivamente los Contadores, que, introducidos como una cuña entre el Secretario y el Depositario, se afirman a costa de uno $y$ de otro.

El Contador-Interventor ya existía, aunque muy vagamente perfilado, en la legislación anterior, pero como una simple posibilidad casi nunca realizada, dado que los Secretarios retienen con mano firme su calidad de Interventores. A esta situación alude expresamente el artículo 27 de la Instrucción de 20 de noviembre de 1845: "las contadurías que han existido hasta ahora en algunos Ayuntamientos se refundirán en secciones de contabilidad de las secretarías... pero siempre bajo la dirección del Secretario".

La entrada formal del Contador dentro de la Administración municipal tiene una historia muy curiosa que empieza en la Ley de 29-9-1865, reguladora de la intervención y contabilidad de las Provincias. En este escalón el proceso tiene su lógica: las Dipu- 
taciones carecen de un patrimonio propio suficiente $\mathrm{y}$, además, en un régimen centralista actúan como puente y pieza de control de la Administración del Estado sobre los Municipios. Por ello, nada tiene de particular que el legislador, a imagen y semejanza de lo que sucede con el Estado (no hay que olvidar que, según el art. 36 de la Ley, "el Gobernador es el ordenador de pagos en el presupuesto de la Provincia»), introduzca aquí un Contador, si bien inicialmente con unas atribuciones muy concretas.

\section{Facultades fiscalizadoras de los Depositarios y Contadores}

En cualquier caso, aquí es donde va a decidirse el destino de la Administración municipal y, más concretamente, de los Depositarios, una vez que -como veremos inmediatamente- los principios de la Administración del Estado terminan llegando a los Ayuntamientos a través del puente de la Administración provincial. Si, de acuerdo con lo dicho, el Contador se introduce como una cuña entre el Secretario y el Depositario, atribuyéndose facultades de uno y otro, es de capital importancia determinar con precisión - cosa, en verdad, nada sencilla - lo que corresponde a uno y otro, para ver lo que queda al Depositario, es decir, para ver hasta qué punto el Depositario pierde por completo sus competencias iniciales o, si, por el contrario, las conserva, al menos inicialmente, aunque ello suponga una reduplicación de funciones: las tradicionales del Depositario, que se mantienen, y las nuevas del Contador, que se superponen a ellas.

A), A tal efecto es significativo estudiar las facultades fiscalizadoras que conservan los Depositarios a pesar de la presencia del Contador. Para ello las normas de referencia son la citada Ley de presupuestos y contabilidad provincial de 20-9-1865 y su Reglamento de la misma fecha. De ambos textos se deduce que el Depositario:

a) Tiene a su cargo los fondos provinciales (arts. 39 de la Ley y 97 del Reglamento), guardados en su arca de tres llaves, conservadas por él, el Gobernador y el Contador (art. 40 de la Ley), en cuya presencia han de celebrarse también los arqueos (art. 109 del Reglamento).

b) Tiene, además, la obligación de rendir las siguientes cuentas: 
- mensual de ingresos y gastos, sin documentación (art. 48 de la Ley),

- anual general documentada (arts. 49 de la Ley y 152 del Reglamento); siendo responsable personal de los alcances que de ellas se deduzcan (art. 54 de la Ley).

c) Fiscaliza formalmente los libramientos de pago en los términos del artículo 41 de la Ley: «El Depositario no hará pago alguno sino en virtud de libramiento expedido por el Gobernador e intervenido por el Contador, en el cual se exprese suficientemente el objeto del gasto y la partida del presupuesto a que se haya de aplicar", que desarrolla así el artículo 130.3 del Reglamento: «es obligación del Depositario... 3..$^{\circ}$ Verificar todos los pagos por obligaciones de la Provincia, expedidos con las formalidades que prescribe el Reglamento".

d) Fiscaliza también materialmente -en control acumulativo al de los demás cargos- el contenido de los libramientos, en los términos del artículo 42 de la Ley: «el Gobernador no expedirá, ni el Contador intervendrá, ni el Depositario pagará libramiento alguno que exceda de la cantidad autorizada en el presupuesto provincial para cada servicio comprendido en él, con arreglo a la distribución mensual».

Este control múltiple tiene, sin embargo, una excepción: «la de los "libramientos interinos"", cuyo régimen aparece regulado en los artículos 99 a 101 del Reglamento.

Art. 99. Sin embargo, de lo dispuesto en el anterior artículo, el Depositario pagará los libramientos que el Gobernador expida en suspenso por las causas y para los efectos que determina el artículo 34 de la Ley, siempre que se hubiesen cumplido las formalidades en el mismo establecidas; pero estos libramientos no podrán abonarse en cuenta hasta que se formalicen, obtenida que sea la aprobación superior.

Art. 101. El Depositario pagará los libramientos interinos que se presenten, siempre que estén intervenidos por el Contador, y se datará su importe en la misma cuenta en que lo haga de los libramientos en suspenso.

e) El medio legal que tiene el Depositario para hacer efectiva su fiscalización es muy sencillo: no pagar, puesto que "cualquier pago que se hiciere faltando algunas de dichas condiciones en el libramiento o en virtud de otro orden o documento, no será de abono en la cuenta del Depositario» (art. 98.2 del Reglamento). 
f) También tiene facultades fiscalizadoras en orden a los ingresos, puesto que puede negarse a recibir los ilegales: "Cuando se disponga que reciba fondos de otra procedencia (distinta de las señaladas en la Ley y Reglamento), podrá negarse a aceptarlos».

g) Y, en fin, por limitarnos sólo a otra de las más importantes, aún no reseñadas, "recauda las rentas y productos de todas clases que por cualquier concepto correspondan a la Provincia» (art. 130.1 del Reglamento).

B) Como se ve, la presencia del Contador no interfiere todavía en algunas de las facultades esenciales del Depositario. Pero, para precisar el ámbito de competencia de uno y otro, importa señalar ahora las del Contador, para poder comprender exactamente el papel que empieza jugando y para valorar desde allí las que va a consolidar más adelante. En realidad es del Secretario de quien procede el bloque mayor de sus atribuciones. Para comprobarlo basta comparar las atribuciones de éste relacionadas en la Instrucción de 20-11-1845, que es de donde se toman, en gran parte de forma literal. Lo que resulta muy lógico. Piénsese que en 1845 el Secretario es también Interventor (art. 33 de la Instrucción). La separación orgánica del Contador implica simplemente una separación funcional de las tareas interventoras del Secretario.

Según el art. 123 del Reglamento, sus obligaciones más importantes son las siguientes:

a) Contabilidad e inventario:

- llevar los libros de cuenta y razón de los ingresos y gastos del presupuesto provincial (n. 4),

- reconocer las cuentas que rinda el Depositario y, subsanados sus defectos, certificar su conformidad, antes de presentarlas al Gobernador (n. 10),

- redactar las cuentas de propiedades y derechos y de presupuestos que el Gobernador debe presentar a la Diputación provincial (n. 12),

- formar, de acuerdo con el Depositario, las liquidaciones generales del ejercicio de cada presupuesto (n. 16),

- formar el inventario de muebles y efectos de la Diputación y Consejo provincial (n. 8).

b) Ingresos y gastos: 
- extender las nóminas para sueldos, pasándolas al Depositario con el libramiento de su referencia (n. 9),

- extender los cargaremes de las cantidades que ingresen en Depositaría (n. 6),

- redactar los libramientos de todos los pagos que hayan de ejecutarse (n. 7).

c) Amplitud de la fiscalización. El artículo 100 describe el alcance de las facultades fiscalizadoras del contable, en unos términos que veremos luego reiterarse durante muchos años, con referencia tanto al Contador como al Depositario: "Cuando el Contador de fondos provinciales creyere que en la ordenación de cualquier pago se infringen las disposiciones de la Ley o de este Reglamento, lo hará presente por escrito y con el debido respeto al Gobernador de la Provincia, expresando las razones en que funda su opinión y citando los artículos de la Ley o del Reglamento que en su concepto se opongan a la realización del pago ordenado. Si el Gobernador insistiese en su primera resolución, dará la orden por escrito y el Contador expedirá sin más demora un libramiento que encabezará con las palabras "libramiento interino"... El mismo día, o al siguiente a más tardar, dirigirá una comunicación al Director General de Administración Local, dándole parte de lo ocurrido». «El Ministro de la Gobernación resolverá en el término de quince días si el pago hecho en virtud de libramiento interino debe, o no, paralizarse» (art. 102).

d) En cuanto a la recaudación, el Contador «vigilará la recaudación de los fondos que corresponden al presupuesto provincial y dará cuenta al Gobernador de cualquier retraso que sufra el ingreso en la Depositaría de las cantidades consignadas en aquél» (n. 11).

\section{De los Contadores provinciales a los Contadores MUNICIPALES}

Hasta aquí todo está, en el fondo, perfectamente justificado, habida cuenta de la subrayada naturaleza mixta de la Administración provincial, a caballo entre la estatal y la municipal. Lo grave es cuando el mecanismo estatal, después de haber saltado a la Administración provincial (que acaba de ser descrita y que no tiene para nuestra historia otra significación que la de explicar lo que va a 
suceder más adelante en los Ayuntamientos) termina pasando a la municipal, como sucede en la Ley municipal de 20-8-1870, cuyo artículo 148.2 despoja definitivamente al Secretario de sus funciones interventoras, que se encomiendan o bien al Contador o bien a un Regidor especializado. Funcionario que, por otro lado, despoja a] Depositario de su competencia para la formación de las cuentas (art. 152). Preceptos que, luego, la Ley municipal de la Restauración, de fecha 2-10-1877, hace suyos, reproduciéndolos literalmente en sus artículos 156 y 160.

El cargo, por lo demás, hace fortuna. Navegando en la estela de su -formalmente- homólogo, el Interventor del Estado, por RO de 4-10-1886 se constituye el Cuerpo de Contadores provinciales y municipales como cuerpo facultativo de la Administración local; que se reglamenta definitivamente por RD de 11-12-1900, en el que ya se consagra una amplísima serie de facultades, tanto para los provinciales (art. 49) como para los municipales (art. 50). Con esta nueva figura - en cuyo estudio no va a entrarse obviamente aquíel destino de los Depositarios parece quedar sellado, siempre bajo la sombra de estos funcionarios, a los que aparentemente están de alguna manera subordinados.

Para comprobar este alza del Cuerpo de Contadores, basta repasar las obligaciones que en el Reglamento se les determinan, enumeradas separadamente para los provinciales y los municipales.

De acuerdo con el artículo 49 las obligaciones principales de los Contadores provinciales son las siguientes:

1. Tener a su cargo la oficina de cuenta y razón y la intervención de fondos provinciales. 2. Llevar los libros principales y auxiliares de contabilidad. 3. Extender los cargarémes de las cantidades que ingresan en caja. 4. Redactar los libramientos de todos los pagos que hayan de ejecutarse y presentarlos a la firma del ordenador, previo examen de los justificantes, negándose a la autorización de todo pago que no tenga consignación en el presupuesto o se oponga a las instrucciones o disposiciones de la superioridad. En estos casos consignará por escrito los fundamentos de su negativa; y si a pesar de ello el ordenador insistiera en el pago, intervendrá la orden sin formalizar el libramiento hasta que resuelva la Dirección General de Administración, a la que deberá dar cuenta directamente en el término de ocho días. 6. Examinar y aprobar las nóminas de los empleados provinciales. 8. Proponer al ordenador las medidas oportunas para promover, cuando sea preciso, la recaudación. 9. Formar las cuentas de presupuestos y de propiedades. 10. Formar, de acuerdo con el Depositario, las liquidaciones gene- 
rales del ejercicio de cada presupuesto. 11. Conservar una de las tres llaves del arca general y asistir a los arqueos.

El artículo 50, por su parte, enumera, entre otras, las siguientes obligaciones de los Contadores municipales, que, como se verá, difieren de las de los provinciales:

1. Tener a su cargo la oficina de cuenta y razón de un Ayuntamiento. 2. Llevar los libros principales y auxiliares de contabilidad. 3. Extender los cargarémes de las cantidades que ingresen en la Caja. 4. Redactar los libramientos de todos los pagos que hayan de ejecutarse y presentarlos a la firma del Alcalde, previo examen de los justificantes, negándose a la autorización de todo pago que no tenga consignación en el presupuesto o se oponga a las instrucciones o disposiciones de la superioridad. 7. Examinar y autorizar las nóminas. 8. Proponer al Alcalde y al Ayuntamiento las medidas oportunas para promover, cuando sea preciso, la recaudación. 9. Formar las cuentas de presupuesto y propiedades. 10. Examinar y censurar las de caudales, que rinda el Depositario. 11. Formar, de acuerdo con éste, las cuentas y balances trimestrales, y las liquidaciones generales del ejercicio de cada presupuesto. 12. Conservar una de las tres llaves del arca y asistir a los arqueos.

A la vista de cuanto antecede, fácil es comprender que los Depositarios han quedado, en cierto sentido, arrinconados. Pero su innegable deterioro no significa, sin embargo, ni mucho menos, que hayan descendido a la condición de simples Cajeros. Sin perjuicio de las atribuciones que han perdido, aún conservan otras de gran importancia, y entre ellas, sus facultades fiscalizadoras -clave para su supervivencia y para valorar la trascendencia de la función-, que son reiteradamente puestas de relieve con especial cuidado en los años sucesivos:

- Así, la RO de 13-6-1878 recuerda la vigencia de la de 25-9-1863, que imponía a los Depositarios la obligación de identificar a las personas de los que cobran, advirtiéndoles que, si los perceptores no saben firmar, lo harán en su presencia dos testigos.

- De acuerdo con el artículo 2 del RD de 19-2-1901, cuando los Ayuntamientos hayan cedido $o$ afectado de cualquier manera $\mathrm{o}$ forma legal, en garantía del canon o intereses y amortización de sus deudas o servicios, algún arbitrio o recargo determinado, no se consentirá, bajo la personal responsabilidad... del Depositario, que se aplique su producto a otra obligación distinta. 
- Y, en fin (por no alargar demasiado la lista, pues con lo anterior basta para demostrar el espíritu que inspira la organización), el artículo 9 del RD de 23-12-1902, sobre orden de preferencia para el pago de obligaciones provinciales y municipales dispone que «los ordenadores de pagos no expedirán, los contadores no intervendrán y los depositarios no pagarán, bajo su personal responsabilidad, libramiento alguno para satisfacer gastos de pago diferible sin que previamente hayan sido abonados los gastos voluntarios mientras no se han solventado todos los obligatorios». Para hacer efectiva esta fiscalización, el artículo 12 de la RO de 28-1-1903 aplica a los Depositarios las facultades que para los Contadores establece la regla cuarta del artículo 49 del Reglamento de 1900, antes transcrita.

Estas facultades parecen, por lo demás, obvia en la práctica administrativa y en los autores de la época. Así, cuando en 1877 publica Fermín Abella su monumental Derecho Administrativo provincial y municipal (seis volúmenes), escribe en la página $684 \mathrm{del}$ tomo primero - sin mayores comentarios, que considera superfluos- que "como el Depositario es el responsable de todo pago que no estuviere arreglado a las partidas del presupuesto, que de negarse a pagar los libramientos del Alcalde que no reúnen estas circunstancias". Y, más todavía, al hablar del Contador, considera que la fiscalización de éste puede afirmarse "por analogía con la que tiene el Depositario» (pág. 682).

En definitiva, la situación es, pues, sobre el papel, aceptablemente clara: la máquina administrativa de las Corporaciones locales se ha complicado con la presencia de una nueva pieza - los Contadores-reflejo de la Hacienda estatal, a los que se atribuyen unas facultades que proceden de los funcionarios que ya existían. Pero conste que el nuevo sistema ni implica la eliminación del Depositario ni tampoco se generaliza con la rapidez que hace presumir la publicación de las normas reguladoras en el Boletín Oficial del Estado. El Depositario tiene una tradición que garantiza su supervivencia en cuanto que sigue considerándose imprescindible en la organización local, por encima de todas las reformas y deterioros. A estos efectos es interesante recordar que cuando al final de la época Isabelina Eustaquio TolEDANo publica su magistral Curso de Instituciones de Hacienda Pública describe (tomo II, pág. 1117) en estos términos el verdadero estado de las cosas: "Sencilla es la organización municipal, compuesta del Alcalde, el Depositario y el 
Secretario del Ayuntamiento. El primero tiene la naturaleza de administrador, el segundo la de Tesorero y el tercero la de interventor; por tanto, cumple el primero el deber de formar y dar la cuenta general con arqueos de fin del año económico municipal; debe también el segundo llevar su cuenta comprensiva de la existencia del año anterior y de las sumas recaudadas y pagadas en el año económico de la cuenta balanceada, para hallar el saldo resultante a cuenta nueva del año futuro. El tercero llevará la suya en orden a la cuenta y razón de ingresos y gastos del presupuesto municipal».

\section{LA DICTADURA: DESARTICULACION FUNCIONAL Y REHABILITACION CORPORATIVA}

El deterioro, antes descrito, se agrava considerablemente durante el reinado de Alfonso XIII. Los Depositarios quedan relegados a un lugar desvaído, rigurosamente subordinado a la influencia creciente de los Interventores; todo ello dentro de un proceso de desconcierto organizativo y atonía política.

Como es sabido, la Dictadura hizo frente a esta situación de manera muy enérgica, buscando en los entes locales una regeneración del país, que se conjetura imposible a nivel estatal. Calvo Sotelo - discípulo, al fin y al cabo, de Maura - intenta en sus célebres Estatutos locales asentar la autonomía de estos entes, reformando su espíritu y estructuras. Y, sin embargo, paradójicamente, su reforma olvidó durante un tiempo a los Depositarios, ya veremos con qué resultados.

Reiteradamente se ha advertido esta laguna en la legislación de la Dictadura. Y no es que los Estatutos no recojan a los Depositarios, puesto que su figura y sus funciones aparecen aceptablemente dibujadas:

- Así tenemos que el Estatuto municipal alude a las tareas de ingresar, custodiar y pagar en los artículos 565 y 566, y a la rendición de cuentas en el artículo 584.

- El Reglamento de Haciendas municipales les dedica nada menos que siete largos y minuciosos artículos (del 81 al 88), aparte de las cuentas previstas en los 129 y 130.

- El Estatuto municipal se ocupa de ellos en los artículos 276 y 277. 
-Y el Reglamento de empleados provinciales, de 2-11-1925, en los artículos 47,48 y 49 .

No hay, pues, olvido de los Depositarios en la legislación de la Dictadura. El gran error no está en la regulación que hace de ellos, sino en lo que no hace, es decir, en no constituir con los mismos un cuerpo nacional, que es cabalmente lo que va a potenciar a los Secretarios e Interventores, como motor y contrapeso de la vida local.

Tal fue la incongruencia cometida y lo que va a lastrar pesadamente la vida interna de las Corporaciones, creando un desequilibrio organizativo y un agravio irritante, en perjuicio tanto de los interesados como del ente.

Ahora bien, la situación resultaba tan absurda que no pudo continuar durante mucho tiempo, puesto que el sistema era contradictorio con los principios básicos de los Estatutos y, sobre todo, con la autonomía. La falta de esta pieza ponía en peligro todo el sistema.

Vistas así las cosas, es claro que sólo había una solución posible: la rehabilitación corporativa de los Depositarios, para equipararlos. Y esta solución como no podía ser menos, terminó imponiéndose por pura lógica antes del fin de la Monarquía. El Real Decreto de 10-6-1930, preparado por la Dictadura, aprobaba el Reglamento del Cuerpo de Depositarios de fondos de Administración local, reparando un error, que pudo haber sido muy grave si hubiera durado más tiempo.

\section{LA SEGUNDA REPUBLICA: PERIODO DE AVATARES}

La existencia de los Depositarios de Administración Local experimenta durante la Segunda República unos avatares desconcertantes. Ya hemos visto que, poco antes de finalizar la monarquía, se ha constituido el Cuerpo, al que había de corresponder, mediante una toma de conciencia corporativa, la gran tarea de articular unas funciones relativamente mal sistematizadas. Durante los primeros años, en efecto, se convocan oposiciones y en el nuevo Cuerpo ingresan funcionarios entusiastas y competentes, que van recuperando el retraso organizativo y que se encuentran en disposición de remediar el deterioro iniciado en 1865 y volver por los antiguos fueros de la Depositaría tradicional. 
Pero de repente, la aparición del D. de 27-2-1934 cambia por completo el panorama. En esta fecha, y sin que hasta el momento hubiera habido una corriente de oposición o una tendencia política que justificase esta medida, el Consejo de Ministros considera derogado el Reglamento de 1930 y disuelto el Cuerpo Nacional. La decisión se debe - tal como explica el Preámbulo del Decretoa un escrúpulo formal en verdad harto discutible, pero que, con razón o sin ella, es el que se tiene en cuenta: la presunción de invalidez de las normas de la Dictadura mientras no se convalidan por la República, sin cuya convalidación quedan degradadas en la jerarquía normativa: "al ser revisadas las disposiciones de la Dictadura y quedar reducido aquel Decreto orgánico al rango de precepto meramente reglamentario, válido solamente en cuanto se conformara con leyes votadas en Cortes, hubo de ser privado de su aparente eficacia».

Ahora bien, con esta medida se había llegado al colmo del absurdo y la nueva legislación municipal se apresuró a rectificar la situación, haciendo caso omiso del brevísimo lapso de tiempo en el que formalmente ha estado disuelto el Cuerpo, puesto que la base XXIII de la Ley de Bases de 10-7-1935 ya advierte que "el Cuerpo de Depositarios estará formado por los funcionarios que en la actualidad pertenecen al mismo (es decir, que no han dejado de pertenecer a él, puesto que el Cuerpo materialmente no se ha disuelto) y por los que ingresen en lo sucesivo» (en términos idénticos al art. 184 de la Ley articulada).

Por otra parte, la regulación de sus funciones es, más bien, escasa; lo que no tiene nada de particular, y no podría ser de otra manera, habida cuenta de que no regula el mecanismo de gestión de su Hacienda, que es el ámbito propio de estos funcionarios. Pero, en cualquier caso, aparecen con toda precisión sus facultades fiscalizadoras, consagrando la recuperación de su importancia:

Art. 166.2. Los ordenadores de pagos, Interventores y Depositarios serán directamente responsables, solidaria y mancomunadamente, de cualquier infracción de tal precepto, o sea, de cualquier pago que ordenaren, intervinieren o efectuaren...

Art. 168.2. Cuando en la Delegación de Hacienda no existiere saldo a favor del Ayuntamiento, el delegado requerirá al Depositario de aquél para que se abstenga de realizar ningún pago antes de haber satisfecho los haberes de los funcionarios. 


\section{FINAL}

A partir de 1945 la situación de los Depositarios de Fondos de Administración local ha permanecido estacionaria, con algunos retoques normativos más o menos importantes, pero no sustanciales. A la cola (por así decirlo) de los otros grandes Cuerpos Nacionales de Secretarios e Interventores, sus miembros han gozado siempre de gran prestigio individual y su función es la que parecía tener mayores posibilidades de futuro, habida cuenta del impacto de la informática. Y sin embargo esta función resultaba singularmente conflictiva por el fallo lamentable de la gestión de los servicios de recaudación, que el legislador no se decidía a abordar frontalmente, manteniendo la inercia de unos «recaudadores" de reconocida ambigüedad institucional, que arrastraba necesariamente la de los Depositarios.

Vistas así las cosas, se ofrecía un claro dilema: o bien potenciar la figura del Depositario encomendándole realmente las funciones que legalmente le correspondían, o bien reducirle a un mero custodio formal del dinero y valores, casi como un jefe de contabilidad. Dilema de solución difícil puesto que para adoptar una decisión hacía falta tener primero una concepción clara de la organización municipal. Y como ésta no existía, durante muchos años (cuyos avatares no se relacionan aquí, puesto que son ya perfecta. mente conocidos) se optó por dejar las cosas como estaban.

$\mathrm{Y}$ ahora, cuando al fin se han abordado, se ha hecho en unos términos de aún mayor ambiguiedad, ya que no se ha contemplado el papel de los Depositarios propiamente dichos, sino que se les ha ipcluido en la problemática general de los Cuerpos Nacionales, que era lo único que parecía obsesionar al legislador.

Dicho con otras palabras: las funciones de Depositaría (Tesorería) y el papel de sus titulares tenían una importancia más que suficiente como para merecer un tratamiento sustantivo e individualizado, puesto que, más mirando al futuro que al presente, era notorio que las cosas no podían seguir estando como estaban. Y sin embargo esto no ha parecido preocupar al legislador actual, quien, variando por completo la perspectiva, ha caído en la trampa de afrontar la cuestión desde la óptica simplista del apasionamiento político de la supervivencia, o no, de los Cuerpos Nacionales, como si éste fuere el problema. Y la decisión ha consistido en mantener 
la ambigüedad existente con la confusión añadida (y absolutamente innecesaria) de la supresión del Cuerpo en los términos que se decían en la introducción de este artículo. De tal manera que, hurtando los planteamientos sustanciales y funcionales, se ha convertido el tema en una cuestión corporativa, que es casi marginal.

El objetivo del legislador era destruir el Cuerpo y así lo ha hecho, personalizando una cuestión que no era individual ni corporativa, sino funcional e institucional. Las razones de tal decisión han sido silenciadas, pero parecen evidentes y son fundamentalmente dos:

Por un lado - y tal como ya se ha apuntado - la ausencia de una concepción clara de la organización municipal, que ha movido al legislador a posponer, una vez más, lo trascendente. $\mathrm{Y}$ por otro lado, el sectarismo de quienes pretendían a toda costa desmantelar a todos los Cuerpos Nacionales como objetivo primario de la reforma local. Razones personales contra los Depositarios no han existido, puesto que si bien es cierto que algunos de ellos son incompetentes y corruptos, éste es un fenómeno inevitable en los grandes colectivos humanos, que no por ello merecen ser disueltos. En líneas generales - que es como deben medirse las situacionesel Cuerpo de Depositarios ofrecía y ofrece una media de competencia, eficacia y moralidad tan digna y suficiente como la de los demás Cuerpos, y aún podría decirse que más elevada, habida cuenta de las dificultades de su gestión.

Lo que de veras suscitaba la animadversión contra ellos -al igual que contra todos los Cuerpos Nacionales- era la conciencia de que representaban una garantía de la legalidad, o sea, una imparcialidad funcional que les colocaba al servicio de la ley y de los intereses generales y no de los intereses individuales de una Corporación concreta. Y sucede que para muchos políticos de campanario, los funcionarios deben ser sus servidores personales, puesto que ellos se consideran los únicos intérpretes de la Ley. Entendida así la autonomía local, resultaba evidente que los Cuerpos Nacionales constituían un estorbo y que había que destruirlos a toda costa. Esto es lo que se pretendía y lo que en gran parte se ha hecho, aunque el legislador, con mayor cordura, no haya cedido del todo a tales presiones y haya optado por una fórmula, que hubiera podido ser peor ciertamente, pero que dista mucho de ser satisfactoria, puesto que se ha quedado en las medias tintas de la ambigüedad. 
En definitiva, nos encontramos hoy en una situación inadmisible: inadmisible por la inseguridad jurídica en que se encuentran unos funcionarios (que, apurando las cosas, sería lo de menos), inadmisible porque se ha dejado pasar la oportunidad de establecer un sistema moderno de depositaría y recaudación (que funcionalmente es gravísimo) e inadmisible $-\mathrm{y}$ esto es, desde luego, lo peorporque se ha abierto el portillo a una variedad autonómica aberrante, que representa un salto histórico hacia atrás, una vuelta al caciquismo que había sido la pesadilla de la Administración Local española durante cien años y que ya se consideraba superado para siempre. En este contexto es como hay que entender la reforma y sacrificio del Cuerpo de Depositarios de Fondos de Administración Local: se ha sacrificado aparatosamente un fenómeno casi secundario para ocultar otras intenciones y otras inhibiciones verdaderamente trascendentales. 